\title{
0 desenho como dispositivo de intervenção: Lilo e Stitch no divã
}

\author{
The cartoon as intervention device: Lilo and Stitch in the couch
}

\section{Cristina Adriana Rodrigues Kern ${ }^{1}$ e Thiago Ribeiro}

\begin{abstract}
Resumo: A psicanálise, enquanto teoria e método de investigação, tem possibilitado a ampliação da compreensão dos fenômenos que ocorrem em diversas áreas do conhecimento, tal como na literatura e no cinema. $\mathrm{O}$ uso dos contos de fadas, a partir da perspectiva psicanalítica tem se mostrado útil no trabalho com crianças. Este artigo trata de um estudo bibliográfico, que tem por objetivo apresentar a possibilidade do uso do desenho animado como uma ferramenta a mais no trabalho do psicólogo, com crianças, no contexto escolar. Para tanto, apresenta algumas semelhanças entre o mundo fantástico dos contos e do desenho animado, sobretudo no que diz respeito à utilidade de ambos enquanto dispositivos para o trabalho com crianças. Em seguida, é analisado o filme Lilo e Stitch, sob o prisma da psicanálise, destacando elementos que possam auxiliar no trabalho do psicólogo com crianças, no contexto escolar. Conclui-se que o desenho animado, assim como os contos, pode ser um recurso promotor de saúde no desenvolvimento infantil é uma ferramenta adicional ao trabalho do psicólogo na educação infantil. Sugerem - se mais estudos, especialmente empíricos, tanto para o uso dos contos, como para o uso do desenho animado, no trabalho com crianças, pelo psicólogo escolar.
\end{abstract}

Palavras-Chaves: Psicanálise; Contos de Fadas; Desenho Animado; Escola.

\begin{abstract}
Psychoanalysis as theory and research method has enabled the expansion of the understanding of the phenomena that occur in various areas of knowledge, as in literature and film. The use of fairy tales from the psychoanalytic perspective has proven useful in working with children. This article is a bibliographical study, which aims to present the possibility of the use of the cartoon, as one more tool in the psychologist's work with children in the school context. It presents some similarities between the fantastic world of tales and cartoons, especially with regard to the use of both as devices to work with children. Then the movie Lilo and Stitch is analyzed from the perspective of psychoanalysis, highlighting elements that can assist in the psychologist's work with children in the school context. It is concluded that the cartoon, as well as short stories, can be a health promoter feature in child development and an additional tool to the psychologist's work in early childhood education. Suggest - if further studies, especially empirical, both for the use of stories, as for the use of the cartoon, in working with children, the school psychologist.
\end{abstract}

Keywords: Psychoanalysis; Fairy Tales; Cartoon; School.

\footnotetext{
1 Professora do Curso de Psicologia da UNESC. Mestre em Psicologia Clínica (UNISINOS). E-mail: cristinak@unesc.net

2 Residente em Saúde Coletiva pela Universidade do Extremo Sul Catarinense. E-mail: psicologia.thiagoribeiro@gmail.com
} 


\section{Introdução}

A psicanálise, enquanto teoria (conjunto de conhecimentos sistematizados sobre o funcionamento da vida psíquica) e método de investigação (busca do significado oculto daquilo que é manifesto por meio de ações, palavras ou produçōes imaginárias, como os sonhos, os delírios, os atos falhos) (Laplanche \& Pontalis, 2001), tem possibilitado a ampliação da compreensão dos fenômenos que ocorrem em diversas áreas do conhecimento, tal como no cinema e na literatura. A perspectiva psicanalítica tem contribuído para 0 entendimento das vivências emocionais mais arcaicas, que em todos os tempos, encontram formas de expressão nos mediadores culturais, que são os mitos, a literatura, o teatro, as pinturas e as artes em geral (Castro, 2009).

Melanie Klein também descobriu no brincar uma forma de diálogo com aspectos inconscientes da criança e, a partir disso, desenvolveu um novo método de psicanálise infantil através da brincadeira, do jogo e do desenho, proporcionando meios técnicos "que se adaptam às mentes das crianças." (Klein, 1970, p. 191). Dessa forma, a ludoterapia foi compreendida como um substituto da associação livre do adulto e, portanto, um facilitador das projeções, advindas do inconsciente, um canal para a expressão dos sentimentos, representação das relações, desejos, fantasias, agressividade e ansiedades das crianças.

Uma das contribuições recentes da psicanálise, direcionada ao universo infantil, ocorreu no âmbito da literatura. Os contos de fadas foram compreendidos pela psicanálise e utilizados como mediadores em psicoterapias (Bettelheim, 1979; Hisada, 1996; Gutfreind, 2003; Sunderland, 2005; Castro, 2009). 0 sentido da ampliação ao uso dos contos ao terreno psicanalíitco está em aproveitar a sua magia e personificaçã̃o das angústias humanas: ao longo dos tempos, eles vêm sendo usados por todos os povos para lidar com suas conflitivas emocionais (Castro, 2009). Bruno Bettlelheim (2009) teve a contribuição de destacar o potencial dos contos enquanto um auxiliar na resolução de conflitos infantis que a criança vivencia nas etapas de desenvolvimento, os quais, muitas vezes não são compreendidos ou são incapazes de serem verbalizados pela criança.

A perspectiva de trabalho com contos se dá na medida em que permitem que a criança elabore as vivências emocionais num mundo simbólico efictício, através dos mecanismos de identificação e de projeção. A identificação se trata do "processo psicológico pelo qual um sujeito assimila um aspecto, uma propriedade, um atributo do outro e se transforma, total ou parcialmente, segundo o modelo desse outro"e, diante desse processo, a personalidade vai "se constituindo e se diferenciando por uma série de identificações" (Laplanche \& Pontalis, 2001, p.226). A criança recebe das histórias uma possibilidade de resolução para suas inquietações, curiosidades e conflitos (Lima, 2010), isso se dá por meio da identificaçãa com os personagens, pois enxerga, sob novas formas, problemas antigos esituações de sua própria vida. A partir da projeção, a criança pode expulsar de si e localizar no outro, seja pessoa ou objeto, qualidades, sentimentos, desejos e mesmo objetos, que desconhece ou recusa em si. Além disso, ela pode assimilar-se a pessoas estranhas ou assimilar a si mesma, pessoas, seres animados ou inanimados, como por exemplo, quando ela ouve história ou assiste histórias e "se projeta neste ou naquele herói" (Laplanche \& Pontalis, 2001, p.374). Assim, a distância temporal e espacial também é um facilitador, pois a criança se vê afastada e vê de longe, seu conflito, que é o mesmo do personagem e não apenas dela (Castro, 2009).

Recentemente, observam-se publicações sobre 0 uso dos contos de fadas, a partir de uma perspectiva psicanalítica, voltado ao contexto escolar
(Castro, 2009; Maia \& Goulart, 2014). Maia e Goulart (2014) realizaram um trabalho com contos (Peter Pan e Pinóquio) em um grupo de crianças com 5 a 6 anos de idade, em uma escola de educação infantil. A partir do contato com os contos, as crianças recriaram as histórias segundo suas vivências e desenvolveram trabalhos que as auxiliaram nos seguintes aspectos: deram rosto aos conflitos inerentes aos seus estágios de desenvolvimento, deram visibilidade às ambivalências, os contos auxiliaram para se autocontrolarem, para a expressividade emocional (por meio de discussão dos sentimentos dos personagens), para a percepção sobre as consequências de suas ações, as crianças tiveram maior concentração nas atividades, favorecendo o seguimento das atividades propostas e realizaram "ensaios" para se prepararem para as cenas da vida real.

0 contato com as histórias imaginadas por outros, seja escutando, lendo, assistindo a filmes, à televisão ou ainda indo ao teatro, ajuda a pensar a nossa existência sob pontos de vista diferentes e "habitar essas vidas de fantasia é uma forma de refletir sobre destinos possíveis e cotejá-los com 0 nosso". (Corso \& Corso, 2006, p.20). Essa ideia éfundamental em psicanálise, enquanto instrumental teórico que vem permitindo a compreensão das formas de expressão do universo infantil, desde a brincadeira livre, a escolha de uma criança por determinada história infantil ou, ainda, 0 interesse da criança por determinados desenhos animados. Todo esse universo pode ser entendido quando há alguém para escutar o imaginário da criança que, por meio de objetos do mundo externo, encontra uma forma mais fácil de expressar (Corso \& Corso, 2006).

Há pouca publicação acerca do uso de desenhos ou filmes como recursos de intervenção do psicólogo no contexto escolar. Contudo, podemos pensar mais sobre essa possibilidade, visto que: "Às vezes, uma história ilustra temores de que padecemos, outras, encarna ideais ou desejos que nutrimos, em certas ocasiões, llumina cantos obscuros do nosso ser". (Bulhões, 2010, p.77). Partindo dessa perspectiva, Umpierre, Gurski e Chaves $(2012$, p.4) desenvolveram um trabalho baseado em filmes, voltado ao público adolescente em uma escola, que fundamentou-se"no cinema como um disparador de questões, de emoções, de ideias e, especialmente, de experiência". Os autores buscaram "resgatar a dimensão potente do cinema enquanto transmissor da experiência, e não como mais um meio pelo qual um saber único e absoluto é partilhado" e, desse modo, foi pensada a experiência do cinema como potencial para "construir junto com os adolescentes um espaço que funcione em um outro tempo e de um outro modo que não o tempo disciplinado da vida escolar" (Umpierre, Gurski \& Chaves, 2012, p.4).

(...) sublinhamos que acreditamos em certa diferença do tempo das imagens do cinema e do tempo das imagens do aparelho televisor. Apostamos que o trabalho com a imagem através da narrativa filmica vai na direção da potencialidade do cinema enquanto uma ferramenta que, através de imagens, não transmite vivência pura; 0 cinema sempre busca narrar uma história, e nesta narrativa podemos trabalhar com algo que convoque os adolescentes, que os provoquem a falar e pensar sobre si, mesmo quando tratam do filme (Umpierre, Gurski \& Chaves, 2012, p.4).

Os autores desenvolveram, portanto, um trabalho inovador através da "utilização de filmes relacionados ao que se problematiza na passagem 
adolescente, buscando criar um espaço de escuta/intervenção com sujeitos que, além de terem acesso limitado aos bens culturais, muitas vezes, carecem de espaços para falar de si e de suas angústias" (Umpierre, Gurski \& Chaves, 2012, p.4). Propuseram, então, realizar a inserção de filmes na escola realmente como um Outro:

(...) um outro lugar de transmissão, um outro modo de transmissão da experiência. Pela via de narrativas que tratam da diversidade da vida - com seus impasses e possibilidades - e que produzem múltiplos discursos, torna-se possível provocar a imaginação, o devaneio, além de reflexões éticas sobre a vida. Busca-se, portanto, fazer uso do cinema como ferramenta para pensar as diversas cenas familiares, sociais, amorosas e escolares que habitam a realidade psíquica de um adolescente. (Umpierre, Gurski \& Chaves, 2012, p.4).

Partindo do pressuposto de que a literatura infantil (contos de fadas) já vem mostrando ser um importante recurso auxiliar na escuta e trabalho com a criança, inicialmente na clínica e, recentemente no contexto escolar, este artigo buscou apresentar a possibilidade do uso do desenho animado como uma ferramenta a mais no trabalho do psicólogo com crianças, no contexto da educação infantil. Conforme as atribuições propostas pelo Conselho Federal de Psicologia (1992), o psicólogo no contexto escolar pode colaborar, dentre outros aspectos, nas relações interpessoais, nos processos intrapessoais, e desenvolver atividades de prevenção, identificação e resolução de problemas psicossociais (CFP, 2008). Desse modo, o objetivo do uso do desenho animado é dispor de mais uma forma de acesso e comunicação com as crianças, e na direção de realizar atividade de prevenção, assim como identificação e resolução de dificuldades. Diante essa realidade, esse trabalho apresenta algumas semelhanças entre o mundo fantástico dos contos e do desenho animado, especialmente no que diz respeito à utilidade de ambos enquanto dispositivos para o trabalho com crianças.

\section{Método}

0 procedimento metodológico para construção desse trabalho partiu da pesquisa bibliográfica acerca do uso da literatura infantil (contos de fadas) como importante recurso auxiliar na escuta e trabalho com a criança. Em seguida, realizou-se uma comparação entre os contos de fadas e o desenho animado, destacando elementos que mostram a viabilidade do uso do desenho animado como dispositivo auxiliar para o psicólogo, no contexto da educação infantil, para a escuta e trabalho com as crianças.

Finalmente, realizou-se a leitura do filme Lilo e Stitch (Sanders, 2002) sob o prisma da psicanálise, destacando elementos que possam auxiliar no trabalho do psicólogo com crianças, no contexto escolar. Assim sendo, apresenta-se uma análise dos personagens, das relações entre eles e de modificações psíquicas importantes que ocorrem ao longo da convivência entre os mesmos.

Foram utilizados artigos da base de dados Scielo, Pepsic e livros impressos.

\section{Os contos de fadas e o desenho animado como dispositivos de intervenção com a criança}

Diana e Mário Corso vêm, há mais de uma década, dedicando-seà análise dos contos infantis. Em seu livro intitulado "Fadas no Divã - Psicanálise nas Histórias Infantis" os autores se debruçam sobre temas como: agressividade, rejeição, rivalidades, medo do abandono, limites e ambivalência do amor dos pais, entre outros (Corso \& Corso, 2006). Os autores afirmam que"muitos analistas, psicólogos e pedagogos reconhecem que existe um aspecto lúdico significativo envolvido nas histórias, mas elas são muito mais do que isso, as crianças usam as histórias como sistemas para organizar sua vida e seus impasses." (Corso \& Corso, 2011, p.20). Seus trabalhos vêm denotando 0 potencial extremamente fértil que a teoria psicanalítica possui para "colocar no divã"a literatura infantil:

A psicanálise sente-se à vontade no terreno das narrativas, (...) uma vida é uma história, e o que contamos dela é sempre algum tipo de ficção. A história de uma pessoa pode ser rica em aventuras, reflexões, frustrações ou mesmo pode ser insignificante, mas sempre será uma trama, da qual parcialmente escrevemos 0 roteiro (Corso \& Corso, 2006, p. 20).

Após estudarem a infância no primeiro livro, em seu segundo livro "A Psicanálise na Terra do Nunca" os autores se dedicam à análise psicanalítica ao terreno dos desenhos animados e séries de T.V. e fazem a seguinte observação:

Convém notar a forte presença da televisão nestas famílias de desenhos animados e séries de que nos ocupamos. Isso era esperado, pois é consoante com o aprofundamento desse meio de comunicação na vida das crianças e dos jovens: agora, sem dúvida, a televisão é um membro da família. (Corso \& Corso, 2011, p. 378).

Os autores ampliam a leitura sobre os simbolismos subjacentes aos personagens e tramas, desde os recentes Shrek, Os Incríveis e Simpsons, aos já consolidados Mary Poppins, História sem fim e Rei Leão, atingindo, ainda, os clássicos Frankenstein e 0 apanhador no campo de centeio. Ocupam-se de problemáticas típicas à Psicologia e à Psicanálise, tais como: a família, a maternidade e à paternidade.

A obra inicia com um capítulo intitulado "A família Amorosa", abordando a valorização de novas configurações familiares. 0 valor agora está no laço familiar em si, ele que deve ser preservado, acima de tudo. Desse modo, abrange 0 tema de que 0 amor entre os seus membros pode não ser o meIhor, nem o ideal, mas deve ser verdadeiro e incorruptível. Independente da situação ou de como sejam, por exemplo, A família Addams, 0 afeto existe apesar de serem, aparentemente, disfuncionais e estranhos (Corso \& Corso, 2011). Neste novo modelo de família, a mulher aparece em melhor papel, graças às suas conquistas sociais e políticas, tanto quanto para os filhos que agora depositam as expectativas de inteligência, bom senso e equilíbrio, valores antes pertencentes à imagem idealizada do pai (Corso \& Corso, 2011).

Dentre os filmes infantis de animação examinados pelos autores, Os Incriveis e Shrek trazem, dentre outros elementos, o humor, através do qual 
se revela uma visão crítica e cômica das situações, bem como a possibilidade de rir de si mesmo:

Agora, o humor mistura-se com as costumeiras doses de magia, animais fantásticos e personagens clássicos da ficção infantil. São os antigos cenários, com seus reis, rainhas, monstros e ajudantes mágicos, convocados para continuar ajudando a elaborar os impasses subjetivos das crianças. Elas se tornaram mais complicadas, portanto, os contos de fada também (Corso $\&$ Corso, 2011, p.1150).

Shrek assemelha-se ao conto de fadas tradicional, visto que a trama acontece em um mundo mágico e no final todas as coisas se resolvem. Além disso, revela uma jornada de crescimento do personagem, que como ajudante mágico o burro "falante", e tudo culmina na formação de uma família unida (Corso \& Corso, 2011). Contudo, os autores defendem a hipótese de que estamos diante de algo inovador: "contos de fadas intimistas", um esqueleto de conto de fadas, recheado com conteúdos contemporâneos, em que a vida interior dos personagens, assim como seus medos e desejos, encontram representação (Corso \& Corso, 2011).

Também são tratados os desenhos animados voltados para a adolescência, tal como em "Rei Leão", abrangendo a maneira como as crianças veem a adolescência como um período de autonomia, porém sem peso da responsabilidade da vida adulta. A partir do desenho, as crianças podem enriquecer seu imaginário a respeito da adolescência, a qual temem, mas a cobiçam (Corso \& Corso, 2011).

0 senso comum nos leva a crer que:

somos aquele que está acordado, que o eixo do nosso ser, o nosso verdadeiro eu, encontra-se assentado na realidade, e não está contaminado por esse caldo múltiplo de fantasias que nos atravessam o tempo todo. Mas, gostemos ou não, somos 0 resultado, o somatório, do desperto com o sonhador, até porque nem sempre é possível delinear uma rígida separação entre os dois, tampouco é possível, nem necessário, definir qual é 0 mais importante. Na prática, somos casados com a realidade, mas só pensamos em nossa amante: a fantasia (Corso \& Corso, 2011, p.46).

Essa nova abrangência da psicanálise apresentada pelos autores ao terreno dos desenhos animados parece bastante inspiradora, na medida em que nos mostra que a"ficçãa ${ }^{3}$ não é apenas uma forma de diversão, é também o veículo através do qual se estabelece um cânone imaginário utilizado para elaborar algum aspecto da nossa subjetividade ou realidade social" (Corso \& Corso, 2011, p.24). Além disso, os autores referem que "as histórias que nos contam, as que vemos em filmes, assim como as que acompanham um brinquedo, (...) também são elementos que se usam para brincar". (Corso \&
Corso, 2011, p.1150). Nessa direção, eles destacam que o elemento central entre os contos, desenhos ou o próprio brincar da criança está em serem subsídios para que as crianças representem seu mundo interno:

Acreditamos que é possível brincar com os animais de um zoológico de plástico genérico da mesma forma do que com os bichos que são personagens de filmes, como Madagascar, Procurando Nemo ou 0 Rei Leão. Usam-se os elementos da história oferecida conforme a vontade ou a adequação para aquela que se está imaginando para brincar: por exemplo, se forem necessários um rei, uma princesa, um pai, podem-se utilizar os brinquedos que já têm esse papel no filme, no programa de televisão, no conto de fadas; se precisarmos de um vilão, por que não lançar mão do boneco de uma personagem maligna? (Corso \& Corso, 2011, p.1150).

Mediante esse panorama, observamos os contos, enquanto "instrumentos lúdicos e transicionais" e que "auxiliam na comunicação de vivências afetivas importantes" (Castro, 2009, p.217) e, a partir dessa e de outras características do universo ficcional, nossa proposta é de que, considerando a presença do psicólogo enquanto mediador, certos desenhos animados possam ser utilizados como dispositivos na direção referida anteriormente por Castro (2009), um auxiliar para que sejam comunicadas vivências afetivas importantes.

Nessa direção, a criança pode se sentir compreendida e, inclusive, aliviada de seus sofrimentos, na medida em que as histórias ou desenhos animados se apresentam como um dispositivo auxiliar a reconhecer o material psíquico como sendo seu. Dessa forma, nas figuras de monstros, bruxas, abandonos, etc. a criança sente que "isso fala de algo que conheço bem, mas nunca tinha pensado" (Castro, 2009, p.219). Assim sendo, ocorre que, ao ser dado um nome a um conhecido não pensado, se torna um alento, pois ele pode ser reconhecido e pensado, abrindo caminho para cadeias associativas (Castro, 2009).

Ainda essa autora, refere que os enredos das histórias produzem uma série de mecanismos psicológicos que são calcados principalmente nas identificações, projeções, introjeções, sublimações e busca da solução dos conflitos. As histórias permitem ver a vida por outro modo, dão suporte para novos aprendizados, como por exemplo, em uma história com dragões e monstros os quais engolem pessoas, a criança pode tomar contato com sua agressividade, voracidade, sadismo oral (Castro, 2009).

As identificações e projeções que a criança faz através dos dispositivos do mundo fantástico são facilitadas pela ausência de tempo, local, nomes próprios, as idades não são especificadas, podendo assim, a criança transitar livremente entre os personagens (Lima, 2010). As categorias dominantes na linguagem simbólica não são o espaço e o tempo, mas intensidade e a associação (Lima, 2010). Dentro disso, Bettlelheim (Lima, 2010) diz se tratar de metáforas de processos do inconsciente, que surgem como cenários através das inúmeras posições identificatórias e projetivas para os desejos, medos e fantasias, oferecendo à criança, recursos para lidar com os mesmos no seu imaginário.

\footnotetext{
3 "Arte de imaginar; Coisas imaginárias" (Michaelis, 2008, p.388)
} 
A criança pequena vivencia diversas frustrações ao longo do seu processo de desenvolvimento psicológico, entre elas: desmame, controle esfincteriano, castração, decepção edípica, necessidade de sair da infância, entre outros. Dispositivos como os contos e os desenhos animados podem oferecer à criança um recurso externo para representar suas dificuldades. Os contos tratam de temas da oralidade, analidade, conflitiva edípica e apresentam uma série de oportunidades de localização externa, daquilo que perturba a criança internamente. Outra característica do mundo das histórias é de apresentar-se como um estímulo de perseverança, pois, independentemente do nível de intensidade dos problemas que os personagens apresentam, a0 mesmo tempo, proporciona à criança um meio de idealização de um futuro (Bettelheim, 1980).

Nesse sentido, a criança tem a possibilidade de focar no herói, o qual vivencia inúmeras adversidades, mas de alguma forma consegue triunfar: "relançamos na fantasia o que nos aflige, mas, em sua versão ficcional, 0 problema encontra alguma saída." (Corso \& Corso, 2006, p.164). Portanto, a criança pode temer as frustrações, mas se suas fantasias tiverem al guma forma de representação, será possível elaborá-las. Logo, o mundo da fantasia presente nos desenhos e contos pode ajudar tanto no alívio de al gum sofrimento, quanto auxiliar no transcorrer das etapas do desenvolvimento infantil (Lima, 2010).

Nesse contexto, o uso de histórias, de formas diversas, "pode auxiliar a criança em elaborações naturais, cotidianas, até mesmo sem necessidades de intervenções terapêuticas" (Bulhões, 2010, p.77). Esse aspecto é um dos fatores que mantém os contos tão vivos, ainda hoje, no cotidiano das crianças. Outro aspecto que auxiliou na manutenção de sua imensa popularidade, foi a transposição dos contos de fadas para o cinema. Walt Disney produziu filmes no formato de desenho animado que encantam as crianças até hoje. A utilização dos desenhos animados como veículo de conto de fadas é chamada por Miranda como "mística disneyana" (Rosa, 2007, p.25). "0 apreço de Disney pelos contos de fadas estava relacionado às boas memórias que ele tinha da infância, marcadas pelo momento que sua mãe parava suas tarefas para contar-Ihe histórias do gênero". (Rosa, 2007, p.25). Ele optou por produzir a sua história favorita de infância, Branca de Neve e os Sete Anões e, considerada a loucura de Disney, o filme entrou em cartaz após quatro anos de produção, em 1937. Branca de Neve foi um sucesso imediato, gerando uma série de outros filmes de contos de fadas, ou baseado neles, como: Pinóquio (1940), Fantasia (1940), Dumbo (1941), Bambi (1942), Cinderela (1950), Alice no País das Maravilhas (1951), Peter Pan (1953), A Dama e o Vagabundo (1955), A Bela Adormecida (1959), 101 Dálmatas (1961), entre outros (Rosa, 2007).

\section{Lilo e Stitch no divã}

Disney produziu desenhos animados com imensa repercussão entre as crianças, dentre eles, Lilo e Stitch, realizado em 2002 dirigido por Dean DeBlois e Chris Sanders e apontado como um dos novos clássicos da Disney. 0 desenho nasceu do convite ao artista Chris Sanders para criar a ideia de um filme e então decidiu aproveitar o personagem "Stitch", criado em 1985 para um livro infantil que acabou não sendo produzido. 0 ambiente isolado onde Stitch criava o caos era originalmente o Kansas rural. Sanders resolveu mudar para o Havaí nunca antes usado em um filme da Disney, e o novo cenário ajudou a definir a trama melhor. 0 codiretor de Mulan, Dean Deblois, foi chamado para colaborar com Sanders no roteiro e direção. A equipe visitou a ilha de Kauai para buscar referências artísticas e conceituais, como a noção havaiana de família, "Ohana”. (Wikipédia, 2005). 0 filme fez tanto sucesso, que o Disney Channel realizou uma série com os personagens de 2003 a 2006 e inspirou o retorno dos personagens em continuações em vídeo: Stitch! 0 Filme (2003), Lilo e Stitch: A Série (2003 a 2006), Lilo e Stitch 2: Stitch has a glitch (2005), Leroy e Stitch (2006), Stitch! (2008 a 2009) (Wikipédia, 2015).

Esse desenho animado já foi explorado e publicado em dois artigos na área de Psicologia (Henriques \& Gomes, 2005; Moreira \& Silva, 2009). 0 primeiro artigo utilizou o enredo do desenho para ilustrar a temática da transmissão psíquica transgeracional e dos mitos familiares (Henriques \& Gomes, 2005). 0 segundo estudo analisou os personagens do desenho na perspectiva analítico-comportamental e discutiu a influência sobre os comportamentos das crianças que 0 assistem, bem como o papel fundamental dos pais como mediadores (Moreira \& Silva, 2009).

0 presente trabalho, por sua vez, apresenta uma leitura psicanalítica dos personagens, das relações entre eles e de modificações psíquicas importantes que ocorrem ao longo da convivência entre os mesmos. Os personagens principais do desenho são Lilo e Stitch, conforme o próprio título já revela, mas a irmã de Lilo também tem um papel muito importante. Lilo é uma criança havaiana de cinco anos, que vive sob a guarda da irmã (Nani) desde a morte de seus pais. Ela é uma menina solidária, como mostra, por exemplo, seu costume de fazer sanduíche de pasta de amendoim, diariamente, para peixes e nadar até 0 alto-mar para alimentá-los. Por vezes, mostra-se impulsiva, tal como, ao ser chamada de louca por outra criança, avançou, mordeu e bateu nela. Suas atitudes parecem advir do seu contexto histórico-vivencial: possui uma história traumática, marcada pela perda precoce dos pais, o que, certamente não passa em branco na vivência e conduta de uma criança. Além disso, Nani, a adulta responsável por cuidar dela, está também sob o efeito do trauma da perda dos pais, além de ter que assumir uma responsabilidade afetiva e financeira, em plena adolescência.

Nani também age impulsivamente em algumas ocasiões, como no momento quando se assusta porque Lilo sumiu do local onde havia ficado de buscá-la e, na corrida para casa, dá um chute num carro que se atravessa à sua frente e que, por azar, é o carro do assistente social que está acompanhando o caso delas. Outro exemplo de sua impulsividade ocorre quando, ao chegar em casa, Lilo está trancada, escutando Elvis e diz para a irmã deixá-la "sozinha para morrer". Em seguida, Nani diz que se ela não abrir, vai colocá-la no liquidificador e pôr a mistura na empada.

Houve um momento importante do desenho em que ambas puderam, após gritaria e ofensas, se acalmar e verbalizar suas angústias. Lilo refere:'Somos uma família quebrada" ao que Nani nega inicialmente e depois confirma que são diferentes. Em seguida elas conversam e Nani diz que não devia ter gritado, ao que Lilo responde que é sua função de irmã. Nos diálogos que foram acontecendo nessa cena, apareceram questões significativas sobre 0 sentimento de perdas, sobre as formas como podem se manifestar essa dor, da necessidade de escutar e lidar com a tristeza, do que fazer mediante essa nova situação e qual o papel de cada uma nessa nova configuração familiar.

Nessa perspectiva, aparecem aspectos interessantes para trabalhar com as crianças que assistem ao desenho. Dentre eles, o tema da composição da família, de que não existe um modelo único (pai, mãe e filhos), nem um modelo que seja melhor ou pior, mas sim, diferente. Desse modo, abre a oportunidade para as crianças lidarem com possíveis dificuldades em relação à sua condição familiar (Moreira \& Silva, 2009).

Outro aspecto demonstrado no desenho éa realidade de que, por vezes, os cuidadores se atrapalham. Contudo, a possibilidade de que consigam 
retomar 0 acontecido e reorganizar a situação é de grande importância para o psiquismo infantil.

Um pouco depois da conversa referida, Lilo pergunta: Você gosta de mim? Sim, responde a irmã, e a pega no colo. Então Lilo conta que mordeu e bateu em uma criança e que as pessoas olham de forma diferente para ela. Após sair do quarto, Nani fica escutando o que a irmã diz e ouve-a pedir"um amigo que não fuja". A partir disso, Nani decide ir a uma instituição para adotar um cachorro, momento em que aparece Stitch em suas vidas. Ele é um ser alienígena condenado ao exílio em um planeta-prisão e conseguiu escapar da polícia interplanetária. Durante a fuga, caiu acidentalmente na Terra e, desde então, para escapar dos outros alienígenas que vieram Ihe capturar, ele se faz passar por um cachorro para ser adotado por Lilo.

Stitch inicia a história quase que invariavelmente agredindo, fugindo e gritando. Sua trajetória vai se reorganizando, à medida que tem, por parte de Lilo, uma forma de maternagem: ela 0 acompanha em suas travessuras e tiranias, nomeando seus sentimentos, auxiliando-0 a colocar em palavras suas ações destrutivas. Nesse ponto o desenho apresenta uma questão muito importante. Lilo, apesar do efeito de uma história traumática, demonstra que foi substancialmente preenchida, narcisizada por seus pais. Aqui se entende 0 termo narcisizada, a partir do processo de narcisismo transvazante do cuidador (estatisticamente a mãe) à criança (Bleichmar, 1994). Esse processo foi proposto por Bleichmar (1994) e é denominado transvazante porque o narcisismo não se restringe ao cuidador, ele transvaza e abrange o outro ser, conferindo-Ihe um lugar, uma existência como alteridade. A autora ressalta que a criança precisa ser fantasmatizável, pois ser pensada pelo outro é condição da vida em sua persistência. Além disso, ser amado e ser pensado implicam "um não apoderamento do corpo por parte do outro: o próprio corpo só chega a ser próprio porque alguém generosamente cedeu uma propriedade sobre uma parte de si mesmo que se torna alheia transvaza" (Bleichmar, 1994, p.4). A partir disso, ela consegue se colocar no lugar de Stitch e demonstra essa empatia em vários momentos em que ele aprontou, tal como o momento em que, depois de seguidos episódios de tirania, ela desenha seu "nível alto de maldade para a sua idade". Ela também leu o conto do Patinho feio para Stich, história escolhida por ele, num momento em que já estava começando a acontecer uma complexização em seu psiquismo:

A experiência, a possibilidade de que algo nos aconteça ou nos toque, requer um gesto de interrupção, um gesto que é quase impossível nos tempos que correm: requer parar para pensar, parar para olhar, parar para escutar, pensar mais devagar, olhar mais devagar, e escutar mais devagar; parar para sentir, sentir mais devagar, demorar-se nos detalhes, suspender a opinião, suspender 0 juízo, suspender a vontade, suspender 0 automatismo da ação, cultivar a atenção e a delicadeza, abrir os olhos e os ouvidos, falar sobre o que nos acontece, aprender a lentidão, escutar aos outros, cultivar a arte do encontro, calar muito, ter paciência e dar-se tempo e espaço. (Umpierre, Gurski \& Chaves, 2012, p. 3).

Com demonstrações de afeto, paciência e conversa, Lilo consegue oferecer um novo destino a Stitch que, por seu turno, vem a lhe preencher um espaço de companheirismo de que tanto precisava. Ao mesmo tempo, apesar da grande necessidade que ela tem de um amigo "que não fuja", a personagem representa uma condição psíquica extremamente elaborada, no sentido de que seu amor não é egoísta: no episódio em que Stitch decide ir embora para, tal como a história do Patinho feio, encontrar sua própria família, Lilo o deixa à vontade para decidir por si.

Quanto à Stitch, "criatura abominável", conforme as autoridades de seu planeta o denominaram, havia sido fadado a ser separado do convívio em sociedade e ser exilado. A história de sua criação propôs um ser que "foi feito para destruir"e, realmente, no princípio é o que ele realmente faz. Em psicanálise, seus atos poderiam ser entendidos como escape da pulsão agressiva, talvez por falha no recalcamento originário, pois a satisfação pulsional se dá de forma direta (atos) (Bleichmar, 1994). Stitch, em sua "configuração inicial" no desenho, não seria considerado um neurótico: "0 sujeito que pensa não éo mesmo sujeito que age; são momentos diferentes. Para pensarmos sobre as coisas e disso gerar significação sobre o que vimos e o que nos acontece - e aí se trata de registro simbólico - precisamos de uma suspensão ao ato". (Umpierre, Gurski \& Chaves, 2012, p.3).

Mas, no mundo das crianças, quem representaria Stitch? No que tange à sua apresentação inicial no desenho, ele poderia ser um representante, seja na escola ou dentro de sua própria família, daquela criança que, muitas vezes, é deixada de lado, incompreendida, aquela que não tem jeito. Contudo, felizmente, nessa história, a criança encontra alguém que Ihe propicia um olhar e intervenções empáticas. Apesar das diferenças, Stitch foi acolhido, aceito e amado e, com a convivência, reorganizou profundamente seu mundo interno. Ao final do desenho, a criatura alienígena já não se identifica mais com o patinho feio, se reconhece como pertencente a um lugar, e repete as palavras de Lilo: "O 'hana significa família e família significa nunca abandonar ou esquecer". Assim, o amor dos pais de Lilo, que Ihe transmitiram essa mensagem, agora reverbera em Stitch.

0 desenho oportuniza a expressão dos sentimentos das crianças espectadoras, a partir dos aspectos apresentados pelos personagens e da relação entre eles e, pode-se pensar na relevância dessa história para as crianças adotadas, pois realça que, mais forte do que os laços consanguíneos são os laços de afeto. Essa abordagem a respeito de crianças adotadas vai ao encontro do que observaram Moreira e Silva (2009) em seu trabalho sobre o mesmo filme.

\section{Considerações finais}

0 presente estudo se propôs a apresentar a possibilidade do uso do desenho animado, como uma ferramenta a mais no trabalho do psicólogo, com crianças, no contexto escolar. Para tanto, foi feita uma pesquisa bibliográfica visando examinar as semelhanças dos contos e do desenho animado, notadamente no que concerne à utilidade de ambos enquanto dispositivos para 0 trabalho do psicólogo com crianças. 0 estudo também analisou o filme Lilo e Stitch, destacando elementos que foram compreendidos enquanto auxiliares no trabalho do psicólogo em educação infantil.

A revisão bibliográfica realizada neste trabalho apresentou uma vasta quantia de trabalhos sobre o uso do conto de fadas, em sua maioria no âmbito da clínica e alguns trabalhos esporádicos na área de psicologia escolar. De qualquer forma, pôde-se constatar a presença de elementos comuns e contributivos para intervenção com a criança, quais sejam: o potencial simbólico 
e salutar dos contos no psiquismo infantil. 0 mundo das histórias é um dos recursos de que as crianças dispõem para ilustrar o mapa imaginário que indica seu lugar, na família e no mundo (Corso \& Corso, 2006), bem como, apresentam possibilidades de soluções criativas para enfrentar problemas, mostrando que novas formas de pensar, ser e agir são possíveis (Castro, 2009).

A literatura trata que, de um modo geral, os personagens das histórias ou dos desenhos, demonstram sentimentos tais como inseguranças, desejos, angústias, medos e cada um de nós pode se identificar com algum aspecto deles. Esses sentimentos, suscitados ao longo do desenvolvimento infantil, são percebidos de forma muito solitária pela criança. Ao escutarem (ou assistirem) as histórias, as crianças podem sentir que não estão totalmente sozinhas nessas vivências, pois se identificam com seu conteúdo. Além dos temas de sofrimento e solidão, há as questões relativas à complexidade da alma humana, além de conflitos como: a dificuldade relativa ao crescimento; 0 medo da morte (das crianças e dos pais); mágoas pelas seduções fracassadas; e o sofrimento decorrente do fato de ter que escolher um amor fora de casa (Corso \& Corso, 2006).

Contudo, percebe-se que esse dispositivo funciona como modalidade de recurso com efeitos terapêuticos, se for considerado o papel fundamental de acolhimento da expressão das crianças, seja mediante a escuta de um conto, seja a partir das manifestações acerca de um desenho animado. Nesses casos, a presença do adulto é essencial, tanto como um organizador dos materiais os quais a criança deverá ter acesso (leituras, filmes, desenhos animados), como acerca das suas expressões, inquietações, curiosidades, acerca dos conteúdos apresentados a ela. A maioria das escolas tem tratado "a arte da narrativa - as canções, 0 drama, a ficção, o teatro, seja lá o que for - mais como uma "decoração" do que como uma necessidade, como algo com que enfeitar o lazer, ou, às vezes, até como moralmente exemplar"(Corso \& Corso, 2011, p.19). Quanto a esse aspecto, tanto o uso de contos de fadas em salas de aula com crianças, quanto os desenhos animados, perdem a função, na perspectiva aqui apresentada, se forem afastados das possibilidades de subjetivação.

Quanto ao desenho Lilo e Stitch, apresenta questões que realmente sensibilizaram as crianças, o que seu imenso sucesso e repercussão comprovaram ao longo de anos após seu lançamento. No olhar da psicanálise, apresenta referências importantes ao psiquismo infantil, tais como: os efeitos da narcisização à criança, a importância do ambiente familiar tolerante e afetivo, o potencial de reorganização psíquica mediante os cuidados do outro, a esperança de encontrar um lugar que ofereça escuta e acolhimento.

Sugere-se, ainda, que sejam "colocados no divã", tal como já deram início os psicanalistas Corso \& Corso (2001), outros desenhos infantis que tenham potencial de benefícios no trabalho do psicólogo com crianças. Uma referência para a análise seria o desenho The Emperor's New Groove (A nova Onda do Imperador), que traz como personagens principais o Imperador Kuzco e o Camponês Pacha. 0 enredo mostra a construção de um vínculo genuíno, pautado pelo respeito, amizade e ética, valores até então ausentes na vida do jovem Kuzco, que pode ser considerado um bom exemplo de patologia do narcisismo, cuja etiologia pode ser vista mediante a relação com sua cuidadora principal (a bruxa Yzma).

Sugere-se que o uso do desenho ou conto possam ser utilizados como ferramentas para trabalhar com os próprios professores nas escolas, no sentido de informá-los acerca da compreensão psicanalítica das personagens, das relações entre eles e dos efeitos psíquicos gerados em quem assiste ou escuta as histórias.
Sugerem-se mais estudos, sobretudo empíricos, sobre o uso deste dispositivo, o qual já vem sendo usado por psicólogos escolares e acadêmicos em estágio, mas que não publicam suas experiências.

\section{Referências}

Bettlelheim, B. (2009). A psicanálise dos contos de fadas. Rio de janeiro: Paz e Terra.

Bleichmar, S. (1994). A fundação do inconsciente: destinos de pulsão, destinos do sujeito. Porto Alegre: Artes Médicas.

Bulhões, L. B. D. (2010) Experiências maternas frente à continência dos medos infantis. Dissertação de Mestrado, Faculdade de Ciências e Letras de Assis, Universidade Estadual Paulista. Recuperado de https://repositorio. unesp.br/bitstream/handle/11449/97571/bulhoes_lbd_me_assis. pdf? sequence $=1$

Castro, M.G.,et al. (2009). Crianças e adolescentes em psicoterapia: abordagem psicanalítica Porto Alegre: Artmed.

Conselho federal de psicologia, (CFP). Disponível em http://site.cfp.org.br/ wp-content/uploads/2008/08/atr_prof_psicologo.pdf

Corso, D., \& Corso, M. (2006). Fadas no divã:psicanálise nas histórias infantis. Porto Alegre: Artmed.

Corso, D., \& Corso, M. (2011). A psicanálise na Terra do Nunca: ensaios sobre a fantasia. Porto Alegre: Penso.

Fromm, E. (1962). A linguagem esquecida: Uma introdução ao entendimento dos sonhos, contos de fadas e mitos Rio de Janeiro: Zahar.

Henriques, M. I. G., \& Gomes, I. C. (2005) Mito familiar e transmissão psíquica: uma reflexão temática de forma lúdica. Psychê, 9(16), 183-196.

Klein, M. (1970). Contribuições à psicanálise. São Paulo: Mestre Jou.

Laplanche, J., \& Pontalis, J.-B. (2001). Vocabulário de psicanálise. São Paulo: Martins Fontes.

Lilo \& stitch. (2019, 30 de Abril). In Wikipédia: a enciclopédia livre. Recuperado de: http://pt.wikipedia.org/w/index.php?title=Lilo_\%26_Stitch\&oldid $=41872904$

Lima, R. B. (2010). O dispositivo conto de fadas na clínica com crianças que apresentam déficit de simbolização. Dissertação (Mestrado em Psicologia), Universidade do Vale do Rio dos Sinos. Recuperado de http://www. repositorio.jesuita.org.br/bitstream/handle/UNISINOS/2907/RobertaLimaPsicologia. pdf? sequence $=1 \&$ isAllowed $=y$

Maia. D. S., \& Goulart. M. B. (2014) De Peter Pan a Pinóquio: 0 desenvolvimento da habilidade de autocontrole e a convivência escolar. Revista Electrónica De Investigación Y Docencia (REID), (11), 147-164.

Michaelis (2008). Moderno Dicionário da Língua Portuguesa. São Paulo: Editora Melhoramentos.

Moreira. L. S., \& Silva. A. B. D. (2009) Lilo e Stitch: Ensinando o "mau" comportamento. Revista Psicologia da (EMP (Instituto de estudos do comportamento). 2 (1), 55-64.

Rosa, L. G. (2007) Dos contos de fadas aos desenhos animados: a comunicação através do processo cíclico das narrativas. Dissertação (Mestrado em comunicação)Programa de Pós-Graduação em Comunicação Social, PUCRS. Recuperado de http://tede2.pucrs.br/tede2/bitstream/ tede/4630/1/395119.pdf

Sanders, C. (Director). (2002). Lilo \& stitch. [DVD] EUA: Estúdios Disney.

Umpierre, A. Gurski, R., \& Chaves, T. (2012) Cine na escola: um dispositivo para a construção de experiências ou a arte de assinar o que se vê. Disponível em http://www.proceedings.scielo.br/pdf/lepsi/n9/a39n9.pdf 